IZA DP No. 9118

The Performance of School Assignment Mechanisms in Practice

Monique de Haan

Pieter A. Gautier

Hessel Oosterbeek

Bas van der Klaauw

June 2015 


\title{
The Performance of School Assignment Mechanisms in Practice
}

\author{
Monique de Haan \\ University of Oslo
}

Pieter A. Gautier

VU University Amsterdam and IZA

Hessel Oosterbeek

University of Amsterdam

Bas van der Klaauw

VU University Amsterdam and IZA

Discussion Paper No. 9118

June 2015

\author{
IZA \\ P.O. Box 7240 \\ 53072 Bonn \\ Germany
}

Phone: +49-228-3894-0

Fax: +49-228-3894-180

E-mail: iza@iza.org

Any opinions expressed here are those of the author(s) and not those of IZA. Research published in this series may include views on policy, but the institute itself takes no institutional policy positions. The IZA research network is committed to the IZA Guiding Principles of Research Integrity.

The Institute for the Study of Labor (IZA) in Bonn is a local and virtual international research center and a place of communication between science, politics and business. IZA is an independent nonprofit organization supported by Deutsche Post Foundation. The center is associated with the University of Bonn and offers a stimulating research environment through its international network, workshops and conferences, data service, project support, research visits and doctoral program. IZA engages in (i) original and internationally competitive research in all fields of labor economics, (ii) development of policy concepts, and (iii) dissemination of research results and concepts to the interested public.

IZA Discussion Papers often represent preliminary work and are circulated to encourage discussion. Citation of such a paper should account for its provisional character. A revised version may be available directly from the author. 


\section{ABSTRACT}

\section{The Performance of School Assignment Mechanisms in Practice*}

Theory points to a potential trade-off between two main school assignment mechanisms; Boston and Deferred Acceptance (DA). While DA is strategy-proof and gives a stable matching, Boston might outperform DA in terms of ex-ante efficiency. We quantify the (dis)advantages of the mechanisms by using information about actual choices under Boston complemented with survey data eliciting students' school preferences. We find that under Boston around $8 \%$ of the students apply to another school than their most-preferred school. We compare allocations resulting from Boston with DA with single tie-breaking (one central lottery; DA-STB) and multiple tie-breaking (separate lottery per school; DA-MTB). DA-STB places more students in their top- $n$ schools, for any $n$, than Boston and results in higher average welfare. We find a trade-off between DA-STB and DA-MTB. DA-STB places more students in their single most-preferred school than DA-MTB, but fewer in their top- $n$, for $n \geq 2$. Finally, students from disadvantaged backgrounds benefit most from a switch from Boston to any of the DA mechanisms.

JEL Classification: $\quad$ C83, D47, 120

Keywords: school choice, Boston mechanism, deferred acceptance mechanism, strategic behavior, ex-ante efficiency, ex-post efficiency

Corresponding author:

Bas van der Klaauw

Department of Economics

VU University Amsterdam

De Boelelaan 1105

1081 HV Amsterdam

The Netherlands

E-mail: b.vander.klaauw@vu.nl

\footnotetext{
* We benefited from valuable comments from Yinghua He, Fuhito Kojima and Alvin Roth, and from seminar participants at various places. We gratefully acknowledge the cooperation of secondary schools in Amsterdam.
} 


\section{Introduction}

In a system of free school choice, students can choose in which school to enroll subject to schools' capacity constraints. Some schools may be oversubscribed while others have empty seats. Many cities around the world, therefore, operate a centralized school assignment mechanism. The most well-known mechanisms are the Boston mechanism and the Deferred Acceptance (DA) mechanism. An extensive literature has analyzed the theoretical properties and shows that these two main mechanisms have important advantages and disadvantages. (e.g. Gale and Shapley, 1962; Roth, 2008; Erdil and Ergin, 2008; Abdulkadiroğlu et al., 2009; Che and Kojima, 2010; Kojima and Manea, 2010; Abdulkadiroğlu et al., 2011). ${ }^{1}$

Most prominently, under the Boston mechanism students do not necessarily reveal their true preferences (the mechanism is not strategy proof). If students have a low acceptance probability at their most-preferred school, for example because the school is popular or they do not have priority at this school, they may rank another school first. The lack of strategy-proofness as property of the Boston mechanism is particularly problematic if the ability to strategize differs by social background. In that case students for disadvantaged backgrounds are more likely to end up at an undesired school than other students.

In contrast, the DA mechanism is strategy-proof. It is optimal for students to reveal their true preferences, because a rejection at the most-preferred school does not reduce the acceptance probability at the next school on a student's preference list. Furthermore, DA results in a stable matching, because no student looses a seat at a (preferred) school to a student who has lower priority at that school. The Boston mechanism does not have this property of a stable matching, but this does not imply that the DA is superior to the Boston mechanism. Abdulkadiroğlu et al. (2011) show that the Boston mechanism can dominate the DA mechanism on the basis of ex-ante efficiency, because the Boston mechanism gives students some scope to express the intensity of their preferences by ranking their most-preferred school first even when the probability of being rejected is high. The DA mechanism does not give an opportunity to signal the intensity of preferences. ${ }^{2}$ As a result, the

\footnotetext{
${ }^{1} \mathrm{~A}$ third mechanism discussed in the literature is the Top Trading Cycles mechanism (TTC). We do not analyze this mechanism here because it is considered undesirable when schools use priority rules (as is the case in our setting). TTC gives students who have priority at a school, for example because an older sibling is enrolled in that school, a higher probability to be placed in any school than students who do not have priority at any school.

${ }^{2}$ This is addressed in the Choice-Augmenented DA mechanism where students can signal their cardinal preferences by sending an additional message indicating their "target school" which is used to break ties at schools. The choice of a target school is, however, a strategic choice (see Abdulkadiroğlu et al. (2014)).
} 
Boston mechanism may result in higher average welfare than the DA mechanism.

It is important to quantify the trade off between Boston and DA, especially for policy makers who have to choose which school assignment mechanism to use. To do so, we have collected a unique data set in Amsterdam that contains information on actual school choices made under (a variant) of the Boston mechanism and information on the ordinal and cardinal preferences of students over schools. With this data set we can: i) obtain an estimate of the degree of strategic behavior under the Boston system, ii) investigate whether strategic behavior depends on characteristics of students and/or the intensity of preferences, and iii) compare the performance of the Boston and DA mechanisms in terms of ex-ante and ex-post efficiency. Ex-post efficiency is defined in terms of counting how often a student has a more favorable outcome under any of the DA mechanisms than under Boston. Ex-ante efficiency is based on the expected welfare of a student under the different mechanisms. So ex-post efficiency considers an ordinal measure of the student's preference, while ex-ante efficiency is based on cardinal measure for these preferences.

Assessing whether students behave strategically and the properties of the resulting allocation, is not easy. Prior research has relied on laboratory experiments or on estimation of structural models. Chen and Sönmez (2006) are the first to examine school assignment mechanisms in the lab. Participants were given valuations for hypothetical schools and would earn an amount equal to the value of the school where they get a place. Participants in different sessions were confronted with different assignment mechanisms. Truth telling was more often observed under DA and TopTrading Cycles (TTC) than under Boston. In contrast to theoretical predictions, DA Pareto dominates TTC, which in turn dominates Boston (see also Calsamiglia et al., 2011).

He (2012); Calsamiglia et al. (2014); Agarwal and Somaini (2014) use structural models of school choice in cases where the Boston mechanism applies, to uncover students' true preferences. They use the estimated preferences to simulate counterfactual assignment mechanisms. He (2012) uses data of almost one thousand students applying to four middle schools in a neighborhood in Beijing that uses a version of the Boston system. In his model agents play Bayesian-Nash equilibrium strategies but are allowed to have heterogenous beliefs. He finds that a change from Boston to DA has more losers than winners and that average welfare is lower under DA than under Boston. Calsamiglia et al. (2014) use data from students applying to elementary schools in Barcelona where students can submit a list of up to ten schools and may have priority based on distance and older siblings. Parents are sophisticated or naive, and are assumed to play equilibrium strategies, where sophisticated 
parents have correct beliefs about admission probabilities. They find that over 90 percent of the parents are sophisticated and that a change from Boston to DA has more losers than winners, while a change from Boston to TTC has more winners than losers. Finally, Agarwal and Somaini (2014) use data from elementary school students in Cambridge (MA). They analyze the benchmark case where all parents are sophisticated and play a Bayesian-Nash equilibrium. This study finds that under Boston 84 percent of the students are assigned to their first-ranked school, while only 75 percent of the students are assigned to their most-preferred school. Furthermore, average welfare is lower under DA than under Boston.

Like the structural papers we use administrative data from a city that assigns students to schools on the basis of (a variant of) the Boston mechanism. However, we do not make assumptions on choice behavior to uncover preferences. Instead, we combine the administrative data with data from questionnaires through which we elicited ordinal and cardinal preferences. Our approach assumes that stated preferences are an accurate measure of actual preferences. We consider this approach as complementary to structural analyses. An advantage of the stated preference approach is that it is more transparent. This turned out to be important when communicating our findings regarding counterfactual assignment mechanisms to policy makers.

In 2013, we complemented the existing application procedure of students choosing a secondary school in Amsterdam with a questionnaire. In this questionnaire students were asked to submit a preference list of up to ten schools and to award preference points to the schools they listed. An accompanying letter emphasized that the responses to the questionnaire would not influence the current application procedure. If some students did not believe this promise, our findings are underestimating the true difference between Boston and DA. We compare Boston with two different versions of the (student-proposing) DA mechanism: DA where one centralized lottery breaks ties among students in the same priority group (single tie-breaking; DA-STB) and DA where each school runs its own lottery to break ties among students in the same priority group (multiple tie-breaking; DA-MTB).

The main findings of our analyses are as follows. Around eight percent of the students disguise their true preferences under the Boston mechanism and apply to another school than their most-preferred school. This does not differ between boys and girls, nor between students from disadvantaged and non-disadvantaged neighborhoods. Applying to another school than the most-preferred school is, however, more likely for students who report a small difference in preference points between their most-preferred school and their second most-preferred school. This concurs 
with the hypothesis that the likelihood of strategic behavior depends on the intensity of preferences.

In terms of ex-post efficiency, DA-STB dominates Boston, that is, if we evaluate the mechanisms in terms of how many students are assigned to one of their mostpreferred $n$ schools, DA-STB does better than Boston for any value of $n$. Both Boston and DA-STB assign more students to their single most-preferred school compared to DA-MTB, but DA-MTB assigns more students to one of their two (or higher) most-preferred schools than DA-STB and (in that order) Boston. To estimate the degree of ex-post inefficiency of the three mechanisms we simulate the fraction of students that would like to switch places without harming other students. The fraction of switchers is highest under DA-MTB (6\%) followed by Boston (4\%), while under DA-STB almost no switches are possible without harming other students.

In terms of ex-ante efficiency, there is not one mechanism that dominates the others. In terms of expected preference points, a majority of the students is better off under Boston than under DA-STB and DA-MTB, while the average number of preference points is higher under DA-STB than under DA-MTB and Boston. We further find that students from disadvantaged backgrounds gain more (lose less) from a switch from Boston to DA-STB or DA-MTB.

The remainder of the paper is organized as follows. Section 2 provides a brief review of the properties of the assignment mechanisms that we focus on in this paper. Section 3 describes the main features of the secondary education system in the Netherlands and describes the Amsterdam version of the Boston mechanism. Section 4 describes the data that we collected for this study. Section 5 presents and discusses the results. Section 6 summarizes and concludes.

\section{School assignment mechanisms}

This section provides a brief review of the Boston mechanism (Section 2.1) and of the DA mechanism (Section 2.2).

\subsection{The Boston mechanism}

The Boston mechanism works as follows. Students submit an ordered list with their top $n$ schools. Schools rank students on the basis of priority, a lottery makes the priority order strict. In the first round students are assigned to the school which they ranked first. Schools with more students than places reject the lowest ranked students. In the second round students who are rejected in the first round are 
assigned to the school they ranked second if this school has remaining places. Again, if more students apply than there are remaining places, the lowest-ranked students of those who apply in the second round, are rejected. This process continues until no more students are rejected.

The Boston mechanism has three properties that are considered undesirable. It is: i) not truth-telling, ii) not stable, and iii) not ex-post Pareto efficient. Not truthtelling means that students have an incentive to apply for a less-preferred school if they perceive that the probability of getting a place at their most-preferred school is low. Not stable (or justified envy) means that a student might be assigned to school $s$ while she prefers $s^{\prime}$ and has a higher priority at $s^{\prime}$ than another student assigned to $s^{\prime}$. Not Pareto efficient means that in the resulting allocation, students might be better off by switching schools without harming other students. The Boston mechanism maximizes the number of students who are placed in the school they ranked first. Given that students may behave strategically, this does not maximize the number of students assigned to their most-preferred school.

A potential advantage of the Boston mechanism - pointed out by Abdulkadiroğlu et al. (2011) - is that it gives students some scope to express the intensity of their preferences. If two students prefer school $s$ to school $s^{\prime}$ but student $i$ has a strong preference for $s$ while student $i^{\prime}$ is almost indifferent, student $i$ is more likely to get a seat at $s$ because student $i^{\prime}$ has an incentive to "strategically" apply for school $s^{\prime}$.

\subsection{The DA mechanism}

The (student-proposing) DA mechanism works as follows. ${ }^{3}$ Students submit an ordered list with their top $n$ schools. ${ }^{4}$ Schools rank students on the basis of priority, a lottery makes the priority order strict. The lottery can be centralized (single tie-breaking; STB) or there can be separate lotteries at each school (multiple tiebreaking; MTB). In the first round students are tentatively assigned to the school they have ranked first. Schools with more students than places reject the lowestranked students. Students who are rejected in the first round are tentatively assigned to the second school on their choice list. Each school then considers students assigned in round 2 and the students it has been holding. Schools with more students than places reject the lowest-ranked students. Hence an oversubscribed school can in the second round reject students it was holding after the first round. This process continues until no students are rejected anymore.

\footnotetext{
${ }^{3}$ The algorithm is due to Gale and Shapley (1962), and first proposed to assign students to schools by Abdulkadiroğlu and Sönmez (2003).

${ }^{4}$ Where $n$ is large enough to avoid that students strategize regarding the choice of which schools to include in the list (cf. Calsamiglia et al., 2010).
} 
DA is strategy-proof (or truth-telling). Since students are tentatively assigned in each step, there is no cost to listing true preferences. A student who is rejected at her favorite school in the first round can still be placed at a school where she has priority in a later round. DA results in a stable allocation. No student loses a seat to a lower priority student and is assigned to a less-preferred school. The allocation is, however, not ex-post Pareto efficient.

The intensity of preferences plays no role in the DA mechanism. Students list their true ordinal preferences and if two students tie in priority at a school, a lottery - and not the cardinal preferences - determines who is accepted.

\section{Context}

\subsection{Secondary education in the Netherlands}

Our data are from students who are finishing primary school and are choosing a secondary school. At this stage, students are 11 or 12 years old. The Netherlands has a tracked secondary education system. The lowest track (pre-vocational secondary education) lasts four years and gives access to subsequent vocational education programs. The intermediate track (general secondary education) takes five years and gives access to professional colleges. The highest track (pre-university education) takes six years and gives access to university education. Which track a student takes is determined at the end of primary education, and depends on the result of a nationwide exit test and on the advice of the primary school teacher.

Students can freely choose among the schools that offer the track at their level. Virtually all schools are publicly funded and there are no substantial tuition fees. All schools prepare their students for nationwide exams at the end of secondary education. The Education Inspectorate assesses the quality of schools and publishes its findings on the Internet. Schools that receive the lowest quality score ("very weak") for three years in a row are closed (if publicly-run) or lose their public funding (if privately-run).

\subsection{School choice in Amsterdam}

Amsterdam is the capital of the Netherlands and is with 750,000 inhabitants its largest city. Each year, around 8000 students transfer from primary education to secondary education. In the city of Amsterdam, there are around 70 secondary schools.

Since 2005, the secondary schools in Amsterdam run a centralized application and admission system. In the first round students can only apply to one school that 
offers their advised track. Schools are allowed to use a limited number of priority rules, i.e. they can grant priority to siblings of current students, to children of staff members, and to students from primary schools with the same pedagogical approach (for example, Montessori or Dalton schools). ${ }^{5}$ The priority rules need to be announced before the application date, so they are known to potential applicants.

When a school is oversubscribed, students are admitted on the basis of priority. A school-based lottery determines the ordering of students who are not in a priority group. Schools may be oversubscribed for some school tracks but not for others. Lotteries are conducted for each school track separately. After losing a lottery, students can only apply to one of the schools that still have places available after the first round. When there are too many applicants for the places that a school still has available in the second round, a lottery is used to determine which of the secondround applicants are admitted. After losing a lottery in the second round, students should again apply to a school that still has seats available after this second round. In the third round, schools consider applications in chronological order. Finally, students who are not placed after the third round, are assigned to a school by a committee. For each track, the total capacity of all schools exceeds the total number of students assigned to this track in Amsterdam.

The system used in Amsterdam is not identical but very similar to the Boston mechanism described in Section 2.1. Under the Boston mechanism, students who are rejected in round $k$ skip round $k+1$ if the $k+1^{t h}$ school on their ordered list has no seats available at that stage. Because the Amsterdam mechanism only asks students to choose one school at the time, rejected students never skip a round. In spite of this difference, the Amsterdam mechanism has similar properties as the Boston mechanism: it is not strategy-proof, the allocation is neither stable nor Pareto efficient, and students have some scope to express the intensity of their preferences.

Our study pertains to the cohort that enrolled in secondary school in September of 2013. These students received the advice from their primary school teacher around December 2012, they participated in the nationwide exit test in February 2013 and received the result of that test in March 2013. The secondary schools organized open days during which prospective new students can visit the schools and gather information between January 72013 and March 1 2013. Each student received exactly one official application form and had to submit that at the school where (s)he applied between March 42013 and March 152013.

Since truth-telling is not a dominant strategy under the Boston mechanism, one

\footnotetext{
${ }^{5}$ Priority on the basis of distance or walking zone is not allowed.
} 
may benefit from knowing at which schools other students apply. In that regard it is important to note that some secondary schools in Amsterdam maintained a website where they report the number of applications they have received so far. Moreover, students who have already submitted their application form to a school can - within the application window - withdraw it from that school and submit it at another school. ${ }^{6}$ These features of the procedure in Amsterdam may help students to coordinate their choices and are, therefore, likely to lead to a better allocation of students to schools.

\section{Data}

Our data describe students who applied for secondary school in Amsterdam in 2013. The data come from two sources. The first source is the register of the centralized application and admission system of the city of Amsterdam, which contains all students. For each student we observe the primary school they attended, the track advised by the primary-school teacher, the score on the final exit test from primary school, the schools to which the student applied in the first and possibly later rounds, whether the student has priority at the school at which (s)he applied, and whether the student was admitted to the school or lost the lottery.

The second source of data is a questionnaire that we administered alongside with the application procedure. All students who were in the final grade of primary school received an application form for secondary education, which they handed in at the school at which they applied. Together with this official application form, students received a questionnaire and an explanatory letter from us. In the letter we explain that the questionnaire is for research purposes to find out whether the current assignment procedure can be improved, and that the responses to the questionnaire do not influence the outcomes of the current procedure. It also emphasizes that data will be treated confidential and that we will not report data on individual students. Appendix A contains a translation of the explanatory letter from Dutch.

The questionnaire is brief and asks to which school the student applied, what the reasons are for applying to this school, whether the student has priority at the school where (s)he applied, whether it is felt that there is a risk of losing the lottery and if so whether this chance is high or low, whether the student would apply to the same school if no single school would conduct a lottery, and how many schools were visited before choosing a school. In addition to these questions, the questionnaire asks students to make a preference list of up to ten schools, and to award points

\footnotetext{
${ }^{6}$ This requires physically going to these schools.
} 
to each school on the list. Students were asked to hand in the questionnaire (in a return envelop addressed to us) at the school where they applied in the first round. Students who did not bring a questionnaire were supposed to receive a copy from the school where they applied. ${ }^{7}$

The instruction for making the preference list, reads as follows (translated from the Dutch instruction):

"We would like to know your preferences for schools in case no single school would conduct a lottery. You should, therefore, not consider the possibility of losing a lottery. This may imply that you place another school at place 1 than the school where you applied. You can only list schools that offer the level of education that corresponds with the recommended level of your child. Hence schools for which your child would qualify.

For each school we ask you to award points. The highest-ranked school receives 100 points. The points you give to another school, can be seen as a percentage of the highest-ranked school. The lower a school is on your list, the fewer points you award. If a school on the list is very close to the previous one, the difference in points is small. For clarity we give some examples."

The examples make clear that the difference in points that are awarded to schools should reflect the difference in valuation that is given to schools. By setting the maximum score for all students to 100 and the minimum to zero we make sure all students have the same range. Appendix A contains a translation of the examples from Dutch.

Figure 1 shows a preference list submitted by one of the respondents. The maximum number of schools that students could include in their preference list equals ten. Note that this restriction does not interfere with truth-telling as would be the case if a preference list submitted for the DA mechanism is restricted in length (e.g. Calsamiglia et al., 2010). We clearly stated that we would like to know preferences for schools in case no single school would conduct a lottery. We can, therefore, assume that the preference list of the questionnaire coincides with the (at most) ten highest-ranked schools that would be submitted under a DA system without restrictions on the length of the preference list.

\footnotetext{
${ }^{7}$ This applies, for example, to students who were enrolled in a primary school outside Amsterdam and applied to a secondary school in Amsterdam.
} 
Figure 1. Example of preference list

Voorkeuren voor scholen (conform het basisschooladvies):

\begin{tabular}{|l||c|}
\hline Naam school & Aantal punten \\
\hline \hline 1. Berlage Lyceum & 100 \\
\hline \hline 2. Hyperion & 90 \\
\hline \hline 3. 4 ge gymnosium & 85 \\
\hline \hline 4. Bar laeus & 70 \\
\hline \hline 5. Cortesius Lyceum & 65 \\
\hline \hline 6. amsterdams lyceum & 65 \\
\hline \hline 7. & \\
\hline \hline 8. & \\
\hline \hline 9. & \\
\hline \hline 10. & \\
\hline
\end{tabular}

Note: The translation from Dutch says: Preferences for schools (in accordance with the advised track level).

Response

The response rate to the questionnaire was 47 percent. This is far above the 20 percent response rate that the Research and Statistics unit of the municipality achieved on a questionnaire about school choice (see Cohen et al., 2012). Our response rate varies substantially between students from different track levels and is highest for students with an advice for the pre-university track. The response rate for this group is 64 percent. Because the assignment and possible lotteries are done separately for students from different track levels, we focus our analysis on this group with the highest response rate. In 2013, 1923 students chose among 29 schools in Amsterdam that offer the pre-university track. Four schools were oversubscribed in the first round and 80 students lost a lottery.

Figure 2 shows the location of the 29 schools and the location of the home addresses of students that applied to these schools. As can been seen in Figure 2, many schools are located close to each other in the center of Amsterdam while the students come from all over Amsterdam and some even from outside Amsterdam. Table 1 reports descriptive statistics for all students with an advice at the preuniversity level in 2013, separately for students who responded and students who did not respond to the questionnaire. This shows that girls are more likely to respond than boys $(\mathrm{p}=0.051)$. Response is also higher among students with a higher score on the final exit test from primary school $(\mathrm{p}=0.000)$. Students who will lose a lottery (i.e. apply to a popular school) are more likely to respond than students who will 
Figure 2. Location of schools and students in the academic track in Amsterdam

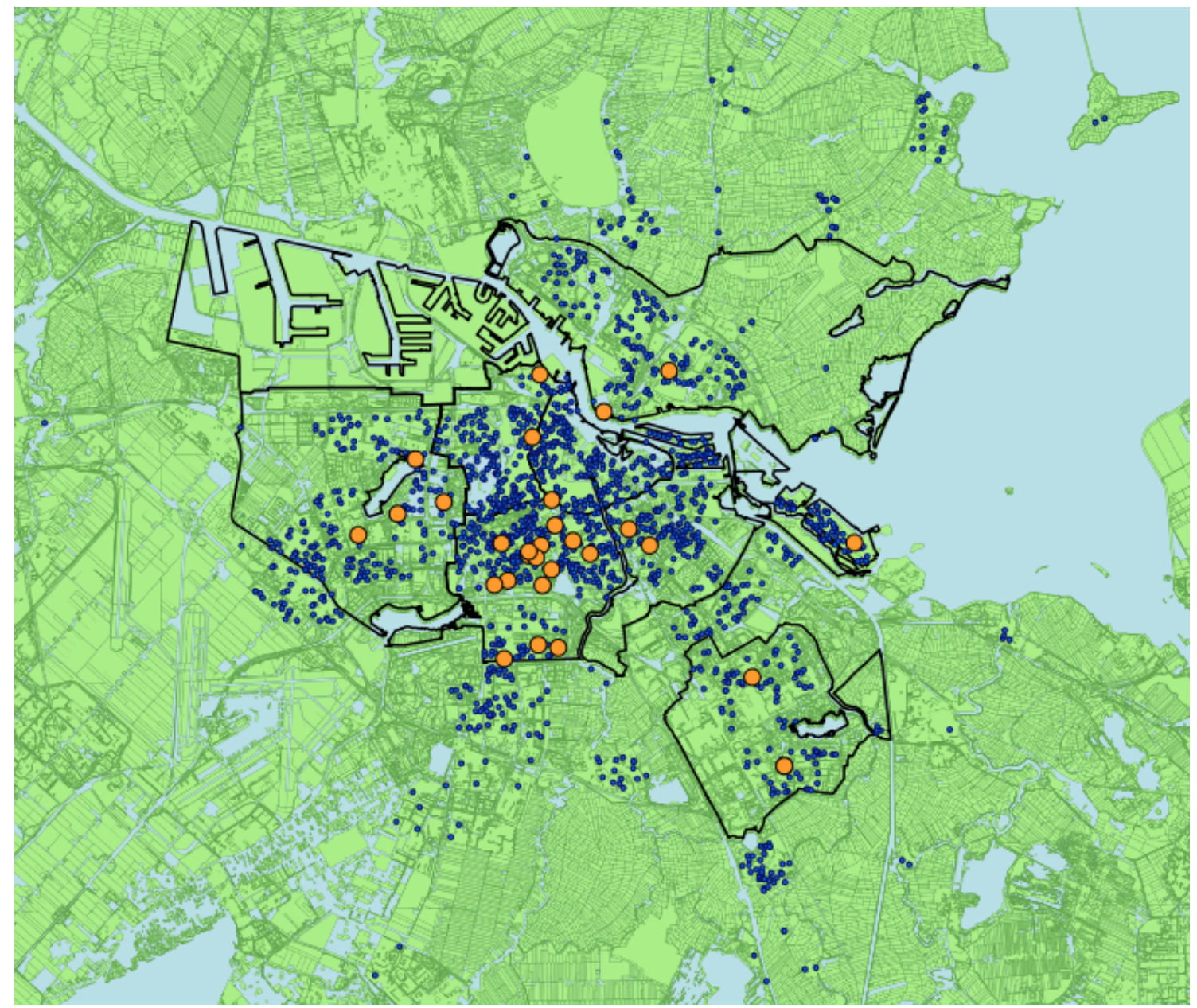

Note: The blue dots are home addresses of students, the orange dots are the location of schools. 
Figure 3. Distribution of number of schools on preference lists

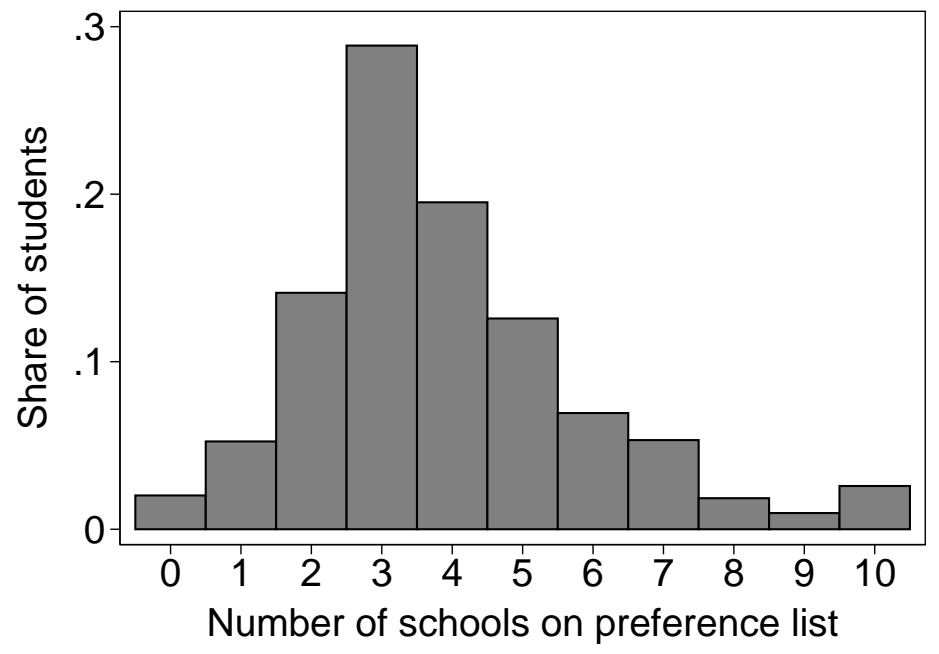

Note: Figure is based on 1240 students with an advice for the pre-university track who responded to the questionnaire.

The final two columns report the GPA and pass rate per school of the cohort graduating in 2012; GPA runs on a scale from one to ten. We took this information from the website of the school inspectorate, which is publicly accessible. These are uncorrected indicators of school quality, which students may use when they choose schools. There are clear differences in GPA and pass rate between schools. Schools with a GPA above 6.5 are schools that exclusively offer the pre-university track.

Respondents could include up to ten schools in their preference list. Figure 3 shows the distribution of the numbers of schools that were actually included in the submitted preference lists. Up to 20 percent of the respondents mention at most two schools. Almost 30 percent of the respondents rank three schools and the remaining 50 percent list at least four schools. Few students fill the complete list of ten schools.

In the subsequent analyses we need to deal with non-response to the questionnaire and with incomplete preference lists. When we analyze strategic behavior, we use sampling weights. To construct these weights, we estimate a logit model of response status using the test score, gender and school of application in the first round as predictors. The sampling weights are equal to the inverse of the predicted probability of response. By using these sampling weights, our estimates of strategic behavior pertain to the population of students at the pre-university level applying to a secondary school in Amsterdam, and not only to those who responded to the questionnaire. The key advantage of using a logit specification with school fixed

all or a share of the students have correct beliefs about the choices of others. Table 2 suggests that in our setting this is a strong assumption as students have difficulties predicting which schools will be oversubscribed. 


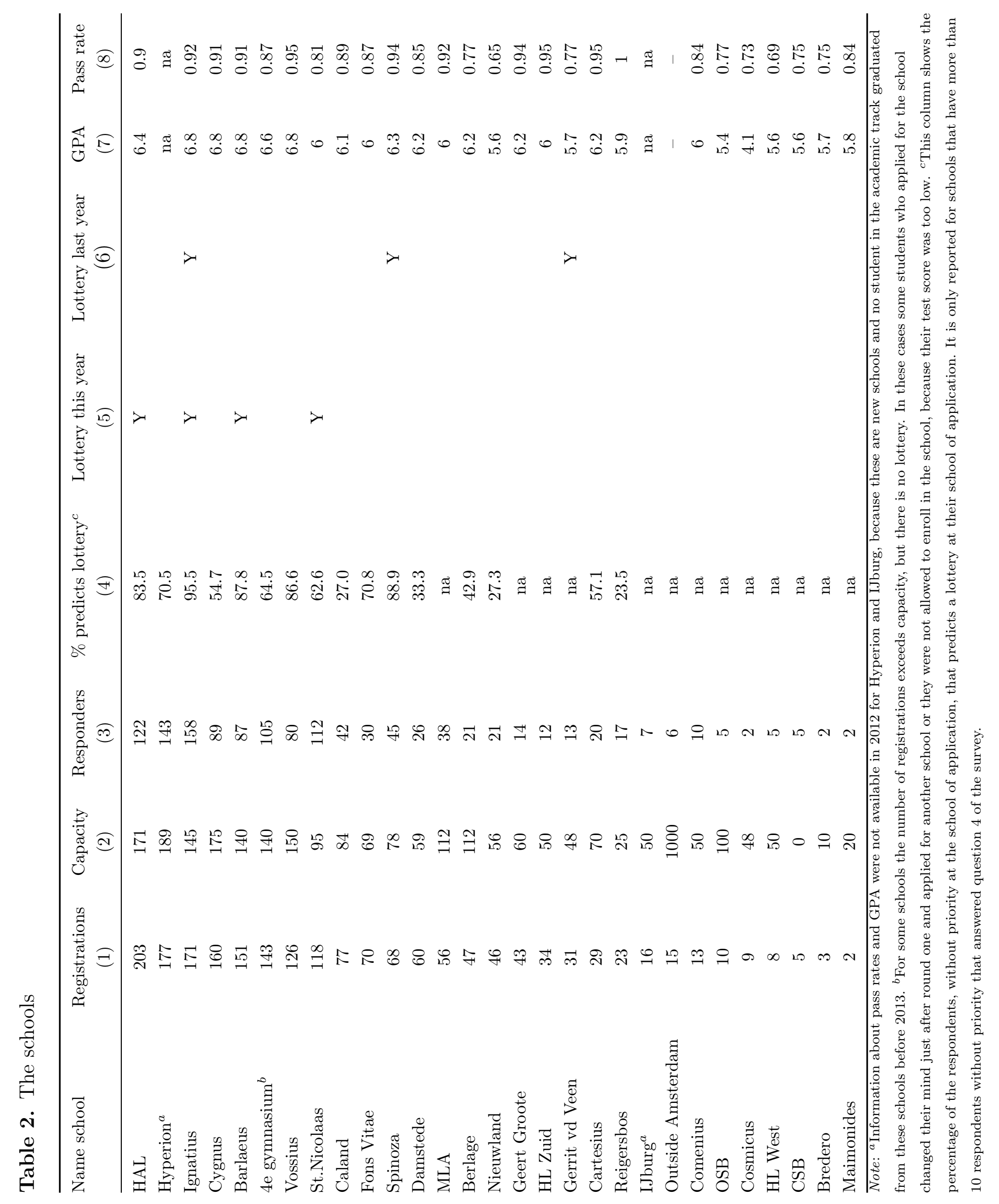


effects is that for each school the weighted sum of survey respondents will exactly match the total number of applicants.

When simulating the different assignment models, we need information on the full population of students. Therefore, for each student who did not complete the survey we sample a replacement student from the pool of students who responded to the survey and applied to the same school. The sampling of a specific student is done using the predicted probabilities from the logit model. ${ }^{10}$ Next, there are quite some students who submitted relatively few schools on their preference list. When students submitted lists with less than ten schools, we complete their lists by sampling additional schools from the distribution of preferences of students applying to the same school. The probability that a specific school is added to the preference list is proportional to how often this school occurs on preference lists of students applying for the same school. For each student we add schools until the preference list contains ten unique schools. The newly sampled schools are ranked but the number of preference points is set equal to zero. This imputation procedure will result in conservative estimates of the performance of the DA mechanism. A student who is assigned to a newly sampled school can occupy the place of another student who ranks that school high and who assigns positive points to that school. Appendix $\mathrm{B}$ shows results from the logit model that was used to create sampling weights and propensity scores.

In the Amsterdam version of the Boston mechanism students apply to one school and do not submit a ranked list of other schools. Such lists are, however, needed to simulate the Boston mechanism. For each student we completed their "Boston list" using information from their preference list. Practically, if a student submitted a preference list with (in order) schools $s_{1}, s_{2}, s_{3}, \ldots, s_{10}$, and the student applied to school $s_{2}$, then we assign this student the following ordered Boston list: $s_{2}, s_{1}, s_{3}$, $\ldots, s_{10}$. This is not necessarily the list that this student would submit if she were to submit a Boston list. When she strategically does not apply to her most-preferred school $s_{1}$, she might not rank this school second on the Boston list. Our procedure to complete the Boston list, helps Boston to perform well. As we will be shown below, Boston places almost 95 percent of the students at the school where they applied. Students who do not receive a place at the school where they applied, do with our procedure still make a chance at their most-preferred schools if it happens

\footnotetext{
${ }^{10}$ For all survey respondents applying to the same school we take the difference in predicted survey-responding probability with the student that should be replaced. Next, we randomly draw one student as replacement, where the replacement probabilities are proportional to a Gaussian kernel in the difference in predicted survey-responding probabilities with a bandwidth of 0.05 . The random draws are with replacement and all results are robust with respect to the bandwidth choice.
} 
that these school were not oversubscribed in the first round.

The data imputation procedure is performed 60 times. After each data imputation the different school mechanisms are simulated 60 times. Our results are, therefore, based on a total of 3600 simulations. Standard errors are based on variation of outcomes when simulating the mechanisms, but not on variation of outcome due to data imputation. The reason is that the focus of this paper is on comparing school assignment mechanisms.

\section{Results}

The results are presented in four subsections. Subsection 5.1 reports results on strategic behavior. The second subsection compares the performance of Boston to DA-STB and DA-MTB on the basis of ex-post efficiency, while Subsection 5.3 compares the mechanisms on the basis of ex-ante efficiency. The final subsection, 5.4, reports how outcomes from the different mechanisms are related to students' social background.

\subsection{Strategic behavior}

Table 3 reports the share of students who did not apply to the school which they ranked first on their preference list. ${ }^{11}$ The shares in the first row are obtained by weighting with the inverse of the estimated probability to respond to the questionnaire. The shares in the second row are unweighted, and these are slightly lower than the weighted shares. The share of students disguising their true preferences equals eight percent (column (1)), and is slightly (but not significantly; $\mathrm{p}=0.763$ ) higher for boys than for girls (columns (2) and (3)). There is also no significant difference $(\mathrm{p}=0.762)$ in strategic behavior between students from different social backgrounds (columns (4) and (5)). We define social background on the basis of average neighborhood income, with disadvantaged (non-disadvantaged) students living in a street where the average taxable income is in the bottom 25 (top 75) percent of the distribution. ${ }^{12}$ Columns (7) and (8) shows that students whose most-preferred school turns out to be oversubscribed, are more likely to apply to another school than their most-preferred school. This indicates that oversubscription is partly predictable, but recall from Table 2 that it is certainly not fully predictable.

\footnotetext{
${ }^{11}$ Students who choose strategically place the school where they apply, on average, on place 2.32 on their preference list.

${ }^{12}$ Average neighborhood income at the 6-digit postal code area is reported by Statistics Netherlands in December 2008. A 6-digit postal code covers a street or part of a street. The top $75 \%$ and bottom $25 \%$ are based on the sample of students with an advice for the pre-university track in Amsterdam in 2013.
} 


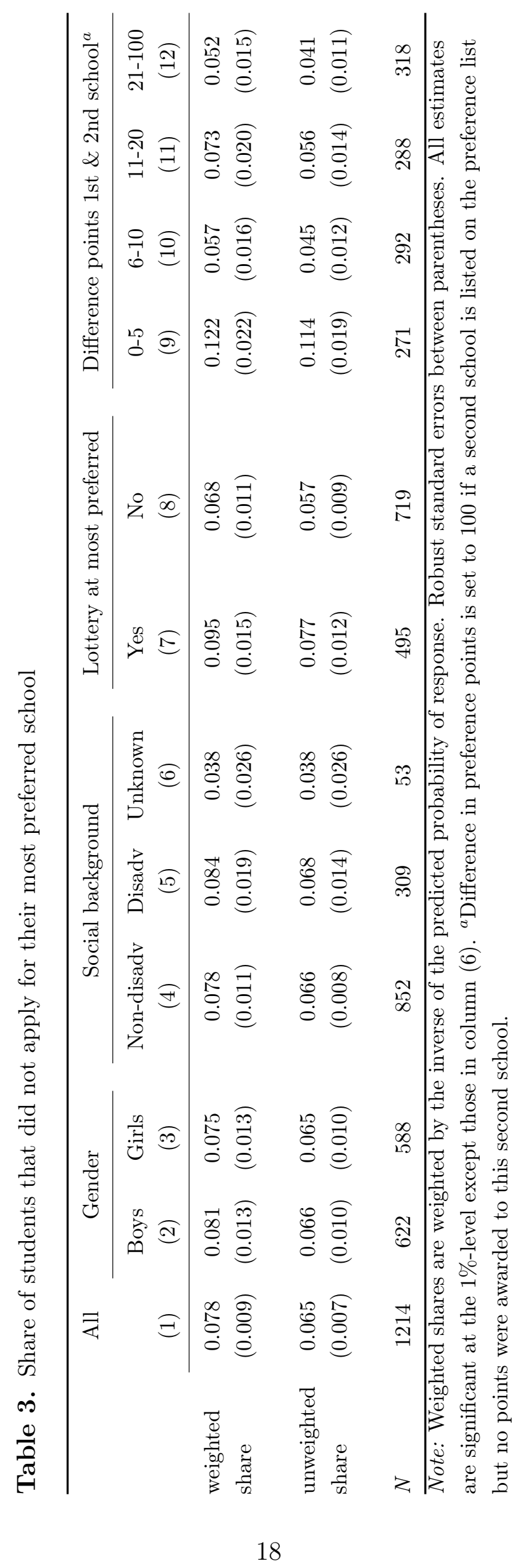


Theory predicts that students with strong preferences for their most-preferred school are less likely to behave strategically than students with weaker preferences (Abdulkadiroğlu et al., 2011). To inquire this, we divide the sample into four (almost) equally sized groups, based on the difference in preference points between the first and second ranked school on students' preference lists. For the first group this difference is between zero and five points and then increases to six to ten (second group), to 11 to 20 (third group), and to 21 to 100 for the fourth group. Columns (9) to (12) of Table 3 report the shares of students that did not apply to their most-preferred school for each of the four groups. In accordance with the theoretical prediction, the share of students not applying to their most-preferred school is largest in the first group (12.2 percent) and smallest in the fourth group (5.2 percent). The ranking for the second and third groups is not monotonic, but the difference in share between these groups is small and not statistically significant $(\mathrm{p}=0.52){ }^{13}$

We, therefore, conclude, that the intensity of preferences indeed plays a role for choices made under the Boston mechanism. Students who have a strong preference for their most-preferred school are less likely to choose strategically than students who are almost indifferent between their first and second ranked schools. This is an important finding, as it fulfills the requirement for the Boston mechanism to have the potential to outperform DA in terms of welfare (ex-ante efficiency).

\subsection{Ex-post efficiency: Boston versus DA-STB and DA-MTB}

In this subsection we compare the performance of Boston with that of DA-STB and DA-MTB on the basis of ex-post efficiency. We compare the mechanisms on the following dimensions: i) shares of students placed in one their most-preferred $n$ schools; ii) shares of students that are ex-post better, equal or worse off under Boston than under DA-STB and DA-MTB; iii) Shares of students that would like to switch places without harming other students; iv) Shares of students that may regret their choices made under Boston. The results in this subsection are only based on students' ordinal preferences regarding schools.

Placement in most-preferred schools. Table 4 compares at which school on their preference list students are placed under Boston, DA-STB and DA-MTB. The first row shows that Boston performs best in terms of placement of students at the school of application. This is not surprising as Boston explicitly maximizes this measure. The results in the second row show that placement at school of application is a

\footnotetext{
${ }^{13}$ The difference between the first and last group is significant $(\mathrm{p}=0.009)$.
} 
Table 4. Placement and mean preference points

\begin{tabular}{lcccccc}
\hline & \multicolumn{2}{c}{ Boston } & \multicolumn{2}{c}{ DA-STB } & \multicolumn{2}{c}{ DA-MTB } \\
\hline Application & 0.947 & $(0.000)$ & 0.828 & $(0.004)$ & 0.780 & $(0.008)$ \\
& & & & & & \\
1st choice & 0.861 & $(0.002)$ & 0.892 & $(0.003)$ & 0.833 & $(0.008)$ \\
2nd choice & 0.073 & $(0.003)$ & 0.064 & $(0.004)$ & 0.138 & $(0.007)$ \\
3rd choice & 0.030 & $(0.002)$ & 0.024 & $(0.003)$ & 0.024 & $(0.004)$ \\
4th choice & 0.016 & $(0.002)$ & 0.011 & $(0.002)$ & 0.004 & $(0.002)$ \\
5th choice & 0.008 & $(0.001)$ & 0.005 & $(0.002)$ & 0.001 & $(0.001)$ \\
6th choice & 0.004 & $(0.001)$ & 0.002 & $(0.001)$ & 0.000 & $(0.000)$ \\
7th choice & 0.002 & $(0.000)$ & 0.001 & $(0.001)$ & 0.000 & $(0.000)$ \\
8th choice & 0.002 & $(0.000)$ & 0.000 & $(0.000)$ & 0.000 & $(0.000)$ \\
9th choice & 0.002 & $(0.000)$ & 0.000 & $(0.000)$ & 0.000 & $(0.000)$ \\
10th choice & 0.001 & $(0.000)$ & 0.000 & $(0.000)$ & 0.000 & $(0.000)$ \\
& & & & & & \\
Mean points & 92.72 & $(0.180)$ & 93.81 & $(0.243)$ & 93.42 & $(0.312)$ \\
Prob. larger than Boston & & & 0.998 & $(0.015)$ & 0.934 & $(0.171)$ \\
\hline Notes: The table reports results of 3600 simulations. Numbers in parentheses are standard errors & \multicolumn{5}{c}{}
\end{tabular}

misleading performance measure. Because a substantial share of students do not apply to their most-preferred school under Boston, the share of students placed in their most-preferred school is (significantly) lower under Boston than under DASTB. Also the difference of 16 percentage points between Boston and DA-MTB in the first row shrinks to three percentage points in the second row.

DA-MTB performs worse than Boston and DA-STB in placing students in their most-preferred school. It does, however, better for the second most preferred school. Figure 4 shows the results of Table 4 cumulatively. For example, the solid line indicates that under Boston 86 percent of the students is placed in their mostpreferred school, 93 percent in their first or second most-preferred school, $96 \%$ in their first, second or third most preferred school, and so on.

Two things in Figure 4 stand out. The first is that DA-STB stochastically dominates Boston; at every value for rank on the preference list, the share that is placed under DA-STB exceeds that of Boston. The second is that there is a trade off between DA-MTB and DA-STB (and Boston). While DA-STB assigns more students to their most-preferred school than DA-MTB, DA-MTB places a larger fraction of students in one of their two (and higher) most-preferred schools. Abdulkadiroğlu et al. (2009) document a similar pattern for New York City where DA-STB does better than DA-MTB for the seven (and lower) most-preferred schools, and DA-MTB does better than DA-STB for the eight (and higher) most-preferred schools. The reason for this pattern with a single crossing point is as follows. Under 
Figure 4. Cumulative distribution of students to schools on their preference list

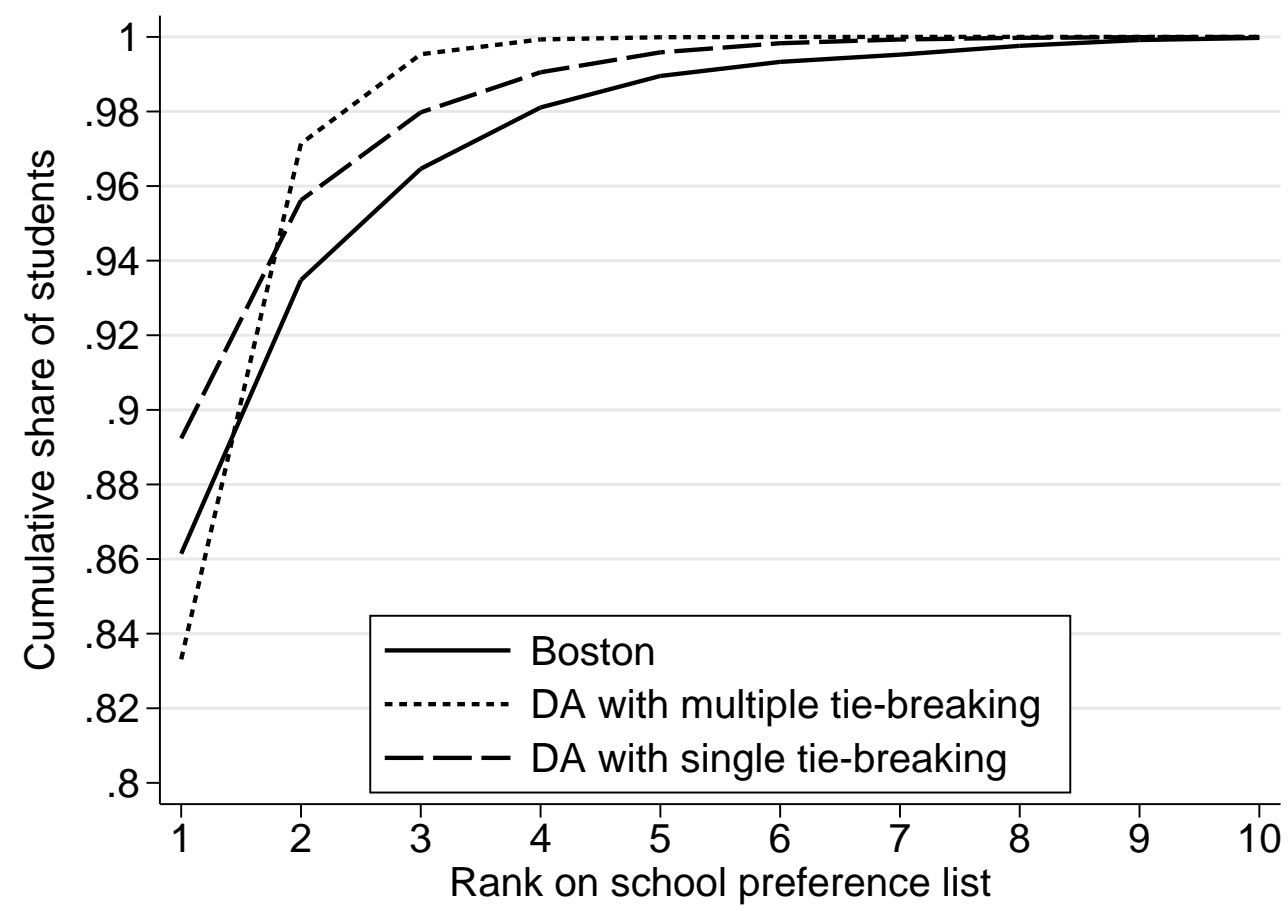

both DA-STB and DA-MTB students who lose the lottery at their first-ranked school are the ones who drew an unfavorable lottery number. When DA-STB is in place, first-round losers carry their bad draw with them to their second-ranked school. When DA-MTB is in place, losers in the first round draw a new - and in expectation more favorable - lottery number at their second-ranked school, making it more likely with DA-MTB than with DA-STB that they capture the place from a student who was tentatively assigned to her first-ranked school in the first round. See Arnosti (2015) for a theoretical discussion of this result.

Shares of winners and losers. The next dimension on which we compare the performance of Boston vis-a-vis the two versions of DA are the shares of students that are better, equal or worse off with Boston than with DA in terms of ex-post assignment. We register after each simulation whether a student gets a seat in a higher, equal or worse-ranked school under Boston than under DA, and compute the respective shares across the 3600 simulations. Our measure for ex-post efficiency is thus based on an ordinal measure for preferences. The average of these shares over all students are reported in columns (1) and (2) of Table 5.

The ex-post efficiency results in Table 5 show that, on average, students have a 12 percent and 11 percent probability to get a seat in a higher-ranked school 
Table 5. Shares of winners and losers, ex-ante and ex-post

\begin{tabular}{|c|c|c|c|c|}
\hline & \multicolumn{2}{|c|}{ Ex-post } & \multicolumn{2}{|c|}{ Ex-ante } \\
\hline & $\begin{array}{c}\text { DA-STB } \\
\text { (1) }\end{array}$ & $\begin{array}{c}\text { DA-MTB } \\
(2)\end{array}$ & $\begin{array}{c}\text { DA-STB } \\
(3)\end{array}$ & $\begin{array}{c}\text { DA-MTB } \\
(4)\end{array}$ \\
\hline Boston $>$ DA & 0.12 & 0.11 & 0.54 & 0.54 \\
\hline Boston $=\mathrm{DA}$ & 0.80 & 0.76 & 0.21 & 0.21 \\
\hline Boston $<$ DA & 0.08 & 0.12 & 0.25 & 0.25 \\
\hline
\end{tabular}

under Boston than under DA-STB and DA-MTB, respectively. And, on average, students have an eight percent and 12 percent probability to be placed in a lowerranked school under Boston than under DA-STB and DA-MTB. This means that although DA-STB stochastically dominates Boston, none of the mechanisms ex-post dominates one of the others.

Efficiency gains from ex-post switching. None of the three mechanisms we examine in this paper result in an (ex-post) Pareto-efficient allocation. That means that some students can improve upon their assigned school without harming others by switching places. The intuition for why this may happen is straightforward. Under Boston it can occur that student $i$ does not apply to her most-preferred school $s$ but applies to and is admitted to her second most-preferred school $s^{\prime}$, while at the same time student $i^{\prime}$ does not apply to his most-preferred school $s^{\prime}$ but applies to and is admitted to his second most-preferred school $s$. Clearly students $i$ and $i^{\prime}$ would both benefit from switching schools. Under DA-MTB it can occur that student $i$ does not get a place at her most preferred school $s$ and gets a place at her lower preferred school $s^{\prime}$. At the same time it can occur that student $i^{\prime}$ does not get a place at her most-preferred school $s^{\prime}$ and gets a place at her lower-preferred school $s$. Again, students $i$ and $i^{\prime}$ would both benefit from switching schools. The same can occur under DA-STB but only when it involves students who have priority at a school which is not their most-preferred school.

In order to get a measure of the Pareto inefficiency of each of the mechanisms we compute the share of students that can improve their position by switching places without harming other students. In particular, we compute all Pareto-improving switches that are possible after Boston, DA-MTB and DA-STB. Figure 5 shows the cumulative shares of students placed in one their most-preferred $n$ schools before 
Figure 5. Boston, DA-MTB and DA-STB before and after switching.

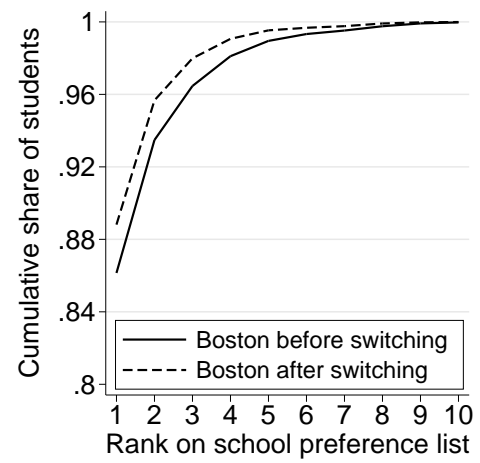

Share switchers Boston: $0.042(0.003)$

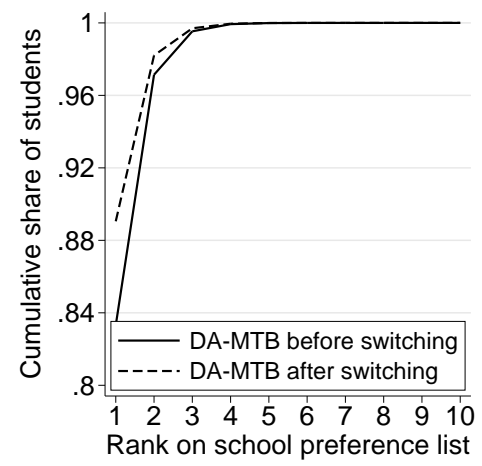

Share switchers DA-MTB: $0.060(0.008)$

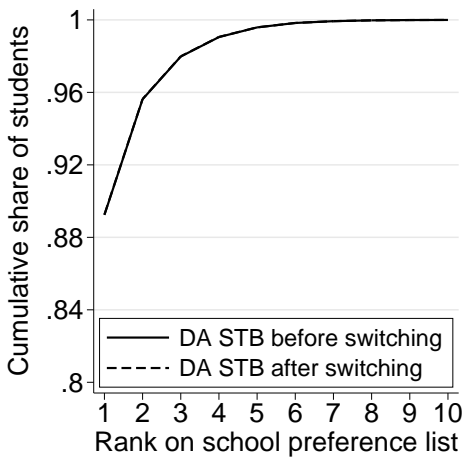

Share switchers DA-STB: $0.000(0.001)$

and after switching. Under Boston four percent of the students can get a seat at a higher ranked school without harming other students compared to six percent under DA-MTB and a very small percentage (rounded to 0.0) under DA-STB.

Regret. Under the Boston mechanism, students make choices that they can later on regret. This can come in two forms. Students who applied to another school than their most-preferred school will regret this choice when it turns out that their most-preferred school was not oversubscribed in the first round. This type of regret is excluded in a Bayesian-Nash equilibrium. Alternatively, students who do not choose strategically may regret not having done so when they are not placed in one of their two most-preferred schools. We calculated the share of students who may regret their choices for these two reasons after each simulation. The average shares are 5.5 percent for the first reason and 2.5 percent for the second reason.

\subsection{Ex-ante efficiency: Boston versus DA-STB and DA-MTB}

As explained in Section 2, the Boston mechanism has the potential to outperform DA in terms of ex-ante efficiency, whereby ex-ante efficiency is defined as efficiency prior to the realization of any lottery necessary to break ties in school priorities. A mechanism is ex-ante Pareto efficient if it is impossible to reallocate probability shares of different schools in such a way that expected utility of some students increases without reducing the expected utility of other students (Abdulkadiroğlu et al., 2011). In order to compare the mechanisms on the basis of ex-ante efficiency we use the number of preference points awarded to schools on the preference lists as a measure of the cardinal preferences of students over schools.

As described in Abdulkadiroğlu et al. (2011) the potential of the Boston mech- 
anism to perform better than DA in terms of ex-ante welfare depends on the correlation of the ordinal preferences over schools, whether or not school priorities are coarse or strict and whether or not strategic behavior depends on the intensity of preferences. In Amsterdam school priorities are very coarse, students either have priority or not and Table 3 shows that students with less intense preferences are more likely to act strategically. In addition, ordinal preferences are correlated as, on average, 13.5 schools would be oversubscribed in case of uncorrelated preferences compared to four oversubscribed schools in reality. ${ }^{14}$ This implies that it is important to compare the performance of Boston to DA, not only in terms of ex-post efficiency but also in terms of ex-ante efficiency.

Shares of winners and losers. In Subsection 5.2 we compared the performance of Boston vis-a-vis the two versions of DA on the basis of the shares of students that are better, equal or worse off with Boston than with DA in terms of ex-post welfare. Columns 3 and 4 of Table 5 show the shares of winners and losers from an ex-ante perspective. We compare a student's expected number of preference points under Boston to her expected number of preference points under DA. The expected numbers of preference points are obtained as an individual student's average numbers of preference points across the 3600 simulations.

The ex-ante results show that for most students the expected number of preference points is larger under Boston than under DA-STB or DA-MTB. The fraction of students being in expectation strictly better off under Boston than under DA equals 54 percent. This means that Boston would beat the DA alternatives in simple majority voting. The reason for the superior performance of Boston on this measure is that a larger share of students get a place at their most-preferred school for sure. With the DA mechanisms this share is smaller because some students run a small risk of losing a place in their most-preferred school to someone that lost a lottery elsewhere.

This is shown in Figure 6 which plots the distribution of the average number of preference points across simulations. It shows that under Boston, 40 percent of the students have an expected number of preference points equal to the maximum of 100. These students do not run any risk of ending up with less than 100 points. The corresponding fractions are lower under the two versions of the DA mechanism. In terms of the minimum number of expected preference points, Boston does, however,

\footnotetext{
${ }^{14}$ We randomly assign a school of application to each of the students, we compare the number of applications to the number of available seats at each school and count the number of oversubscribed schools. We perform these steps 100 times and take the average to compute how many schools would be oversubscribed, on average, in case of uncorrelated preferences
} 
Figure 6. Distribution of average number of preference points across simulations

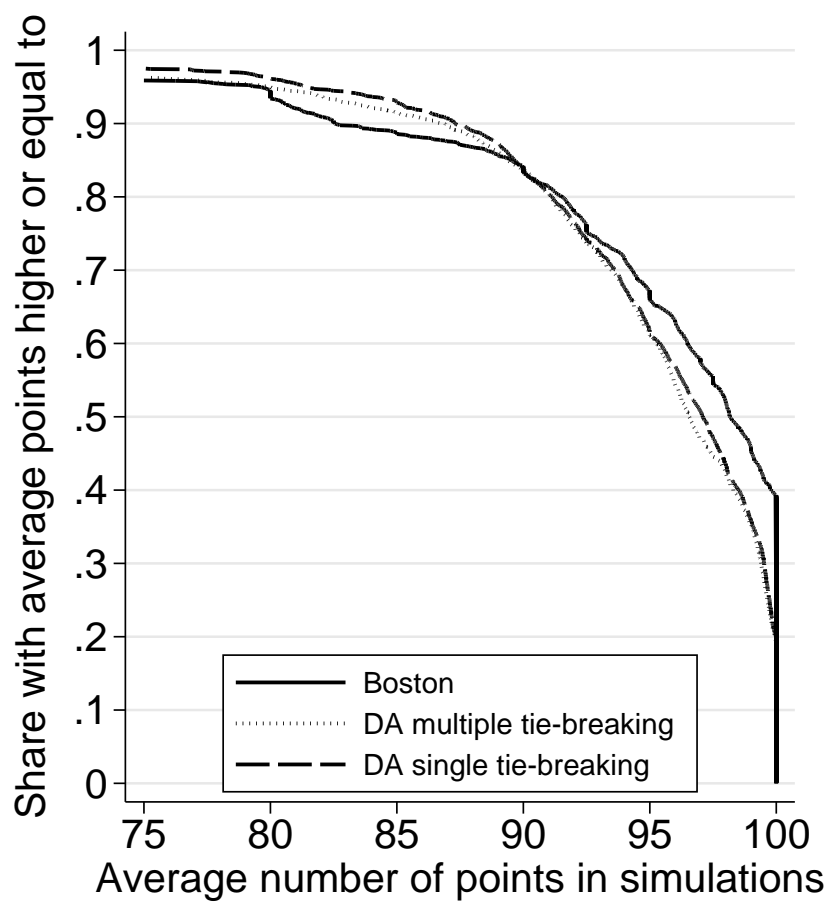

not dominate the other two mechanisms. For example, the fraction of students that expect at least 85 preference points is larger under the DA mechanisms than under Boston.

Average preference points. The results on shares of students that are ex-ante better, equal or worse off, are based on students' cardinal preferences but do not compare preference points across students. We now go one step further and assume that preference points can be compared across students. Under this assumption we can average preference points over different students. After each simulation we calculated for each mechanism the average number of preference points that students award to the school to which they are assigned. The penultimate row of Table 4 reports the means and the standard deviations of these averages over the different simulations. The final row reports the fractions of the simulations in which the average number of preference points for Boston was smaller than the average number of preference points for DA-STB and DA-MTB, respectively.

The mean number of preference points is highest for DA-STB followed by DAMTB, and Boston. DA-STB outperforms Boston in 99.8 percent of the simulations, DA-MTB does so in 93.4 percent of the simulations. This shows that in spite of Boston's potential to capture cardinal differences in students' valuations of schools, it performs worse in terms of average welfare points than DA-STB and DA-MTB. 
Table 6. Shares of winners and losers, ex ante and ex post, by social background

\begin{tabular}{|c|c|c|c|c|c|c|c|c|}
\hline & \multicolumn{4}{|c|}{ Non-disadvantaged } & \multicolumn{4}{|c|}{ Disadvantaged } \\
\hline & \multicolumn{2}{|c|}{ Ex-post } & \multicolumn{2}{|c|}{ Ex-ante } & \multicolumn{2}{|c|}{ Ex-post } & \multicolumn{2}{|c|}{ Ex-ante } \\
\hline & STB & MTB & STB & MTB & STB & MTB & STB & MTB \\
\hline Boston $>$ DA & 0.12 & 0.11 & 0.56 & 0.56 & 0.13 & 0.13 & 0.46 & 0.46 \\
\hline Boston $=\mathrm{DA}$ & 0.80 & 0.76 & 0.19 & 0.19 & 0.81 & 0.77 & 0.27 & 0.27 \\
\hline Boston $<$ DA & 0.09 & 0.13 & 0.25 & 0.25 & 0.06 & 0.10 & 0.27 & 0.27 \\
\hline
\end{tabular}

Notes: The table reports results of 3600 simulations. The ex-ante shares are based on a comparison of the expected number of preference points over all simulations of individual students under the different mechanisms. The ex-post shares are based on a comparison of the rank on the school preference list of individual students under the different mechanisms after each simulation and are averaged over all simulations.

Summing up, ex-ante most students expect a better assignment under the Boston mechanism than under any of the DA mechanisms, but differences are small. However, those who are better off under DA, are often much better off than under Boston.

\subsection{Heterogenous effects}

In this final subsection, we inquire whether the different mechanisms affect students from different social backgrounds differentially. Recall that in Table 3 we found no evidence of different degrees of strategic behavior between students from lower or higher-income neighborhoods.

Table 6 reports the shares of students of different social backgrounds, defined on the basis of average neighborhood income as described in Section 5.1, who are ex-ante and ex-post - better, equal and worse off under Boston in comparison with DA-STB and DA-MTB. According to the ex-post results there are no substantial differences between disadvantaged and non-advantaged students. In contrast, the ex-ante results show differences in the shares of winners and losers between disadvantaged and non-disadvantaged students. While a majority of the non-disadvantaged students is best off with the Boston mechanism, this is not the case for disadvantaged students. The percentage of disadvantaged students that are better off under Boston equals 46 percent which is 10 percentage points lower compared to the nondisadvantaged students.

In Figure 7 we have plotted for each student the expected number of preference points under Boston against the expected number of preference points under DA-STB (left-hand graph) and DA-MTB (right-hand graph). A vast majority of the students are located in the top-right corners of the graphs meaning that both 
Figure 7. Expected points Boston versus DA-STB and DA-MTB
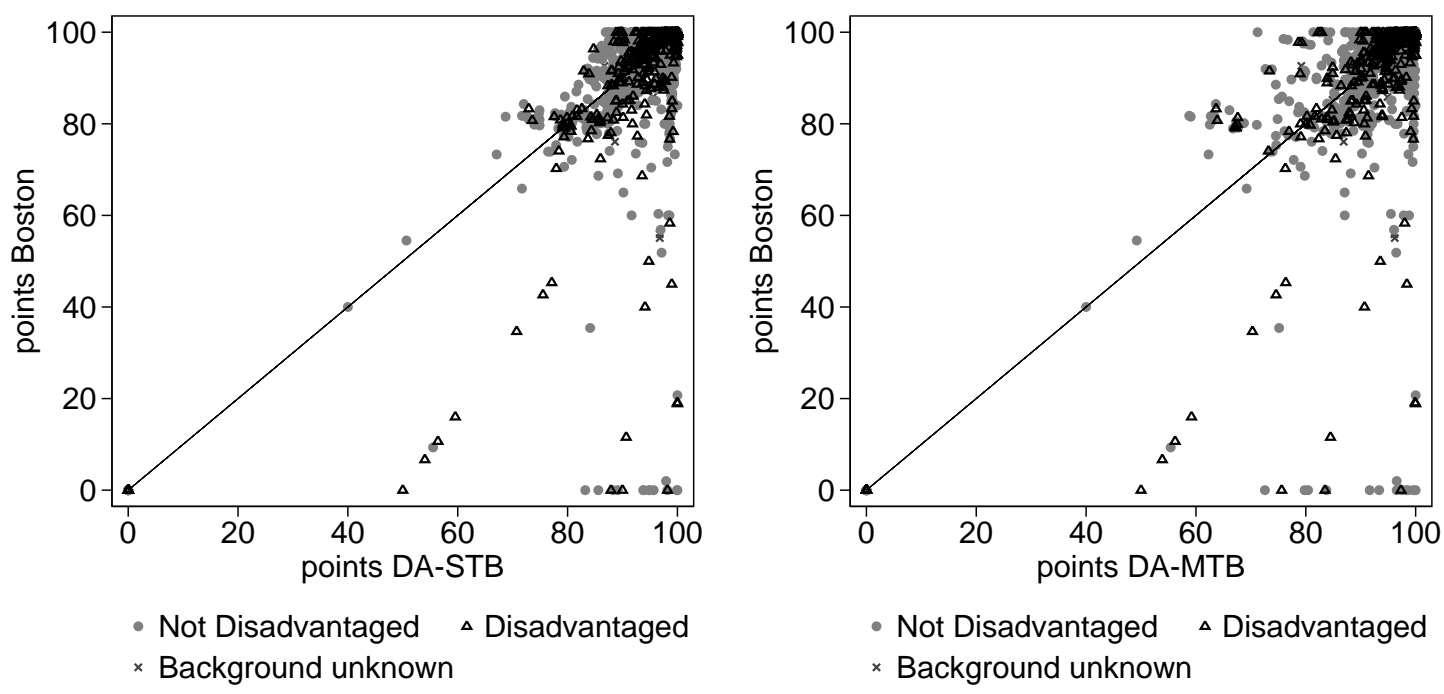

mechanisms give them expected preference points equal to or close to 100 . At the same time we observe that a fraction of the students is substantially worse off under Boston than under DA-STB or DA-MTB. Closer inspection of the graphs suggests that non-disadvantaged students are overrepresented amongst students that benefit from Boston, while disadvantaged students are more likely to be harmed by Boston.

We test this assertion formally by regressing students' difference in expected preference points between Boston and DA-STB (DA-MTB) on the dummy variable for having a disadvantaged background. Columns (1) and (2) in Table 7 report the results. The top panel reports results without other student characteristics, while the bottom panel shows results that are obtained from regressions which also include students' (standard-normalized) score on the exit exam from primary school and a dummy which takes the value one for girls. The estimated coefficients indicate that a switch from Boston to DA-STB or DA-MTB benefits disadvantaged students more (or harms them less) than non-disadvantaged students. The difference equals 1.2 preference points. Column (3) shows that there is no differential effect by social background from a switch from DA-STB to DA-MTB. The last column shows that students from a disadvantaged social background benefit less from Pareto-improving switches after DA-MTB.

The other results in Table 7 indicate that students with a high score on the exit exam in primary school benefit less (or are harmed more) from a switch from Boston to DA-STB or DA-MTB than students with a low score. Students with a high score on the exit exam benefit more from complementing DA-MTB with switching. There are no differential gains from switching from one mechanism to another related to 
Table 7. Relation between difference in points of two mechanisms and background characteristics

\begin{tabular}{|c|c|c|c|c|}
\hline & $\begin{array}{l}\text { DA-STB - } \\
\text { Boston } \\
\quad(1)\end{array}$ & $\begin{array}{c}\text { DA-MTB - } \\
\text { Boston } \\
(2)\end{array}$ & $\begin{array}{c}\text { DA-MTB - } \\
\text { DA-STB } \\
(3)\end{array}$ & $\begin{array}{c}\text { DA-MTB }+ \text { switch } \\
\text { DA-MTB } \\
(4)\end{array}$ \\
\hline Disadvantaged & $\begin{array}{c}1.295^{* *} \\
(0.647)\end{array}$ & $\begin{array}{c}1.182^{*} \\
(0.645)\end{array}$ & $\begin{array}{c}-0.113 \\
(0.138)\end{array}$ & $\begin{array}{c}-0.372^{* * *} \\
(0.130)\end{array}$ \\
\hline Disadvantaged & $\begin{array}{c}1.212^{*} \\
(0.641)\end{array}$ & $\begin{array}{c}1.127^{*} \\
(0.641)\end{array}$ & $\begin{array}{c}-0.085 \\
(0.140)\end{array}$ & $\begin{array}{c}-0.335^{* * *} \\
(0.129)\end{array}$ \\
\hline Test score & $\begin{array}{c}-0.425^{* * *} \\
(0.082)\end{array}$ & $\begin{array}{c}-0.365^{* * *} \\
(0.083)\end{array}$ & $\begin{array}{c}0.060^{* * *} \\
(0.020)\end{array}$ & $\begin{array}{c}0.050^{* * *} \\
(0.016)\end{array}$ \\
\hline Female & $\begin{array}{c}0.235 \\
(0.509)\end{array}$ & $\begin{array}{c}0.340 \\
(0.515)\end{array}$ & $\begin{array}{c}0.105 \\
(0.120)\end{array}$ & $\begin{array}{l}-0.078 \\
(0.107)\end{array}$ \\
\hline
\end{tabular}

Notes: Each column reports results from a separate OLS regression. The dependent variables are the difference in expected number of preference points for each student calculated on the basis of 3600 simulations. The regressions also include a dummy variable for unknown background.

students' gender.

\section{Conclusions}

The recent theoretical literature has pointed out that there is a trade off between two main school assignment mechanisms, Boston and DA. While DA is strategyproof and gives a stable matching, Boston might outperform DA in terms of ex-ante efficiency. In this paper we have quantified the advantages and disadvantages of the mechanisms by using information about actual choices under the Amsterdam version of the Boston mechanism complemented with data from a survey which elicits students' true cardinal preferences regarding schools.

Consistent with theory we find that under the Boston mechanism some students disguise their true preferences and apply to another school than their most-preferred school. This occurs more frequently among students who value their most-preferred school not so much higher than their second most-preferred school.

When we evaluate mechanisms in terms of how many students are assigned to a school from their most-preferred $n$ schools, DA-STB does better than the Boston mechanism for any value of $n$, while DA-STB (and Boston) do better than DA-MTB for $n=1$, whereas DA-MTB does better for $n>1$.

When we evaluate mechanisms in terms of the mean number of preference points that students give to the school to which they are assigned, DA-STB does better than DA-MTB, which in turn does better than the Boston mechanism. Hence, in 
spite of the potential that the Boston mechanism has to capture cardinal differences in students' school valuations, it performs worse in terms of average welfare than the two versions of the DA mechanism.

We want to emphasize that four features of the situation in Amsterdam and our empirical approach give the Boston mechanism the best possible chance. First, some schools maintain websites that inform students about the current number of applications. This information provision makes it more likely for students to coordinate on an equilibrium. Second, some students may not have believed our promise that responses to the questionnaire have no influence on the current assignment procedure, and may, therefore, have reported their strategic choice as their true preference. Third, for students who have not reported a complete list of ten schools, we have imputed new schools based on the preference distribution of other students applying to the same school and have set the number of preference points for the imputed schools equal to zero. As a result, students with an incomplete list can under the DA mechanism occupy the place in a school of a student who awards positive preference points to that school. Finally, in the Amsterdam version of Boston, students only report (apply to) their first choice. We have completed students' Boston lists using information from the preference lists they submitted. This procedure makes it more likely that students who do not get a place in the school to which they applied are placed in a school high on their preference list.

We have presented our results to the organization of secondary schools boards in Amsterdam. The members of this organization have unanimously decided to replace the Amsterdam version of the Boston mechanism by the DA-MTB mechanism. The key reason to choose DA-MTB over DA-STB is that it spreads the "pain" of a shortage of places at some popular schools, more equally. This was considered more important than the larger fraction of students that may want to switch schools under DA-MTB than under DA-STB. The new system is first used in May 2015 to assign students to secondary schools for the academic year starting in September 2015. The new system allows students to submit a preference list with as many schools as they want. Students are informed that under the new system they cannot improve their assignment by submitting a list that deviates from their true preferences.

\section{References}

Abdulkadiroğlu, A., Che, Y.-K., and Yasuda, Y. (2011). Resolving conflicting preferences in school choice: the Boston mechanism reconsidered. American Economic Review, 101(1):399-410. 
Abdulkadiroğlu, A., Che, Y.-K., and Yasuda, Y. (2014). Expanding "choice" in school choice. AEJ Microeconomics, Forthcoming.

Abdulkadiroğlu, A., Pathak, P. A., and Roth, A. E. (2009). Strategy-proofness versus efficiency in matching with indifferences: Redesigning the NYC High School match. American Economic Review, 99(5):1954-78.

Abdulkadiroğlu, A. and Sönmez, T. (2003). School choice: A mechanism design approach. American Economic Review, 93:729-747.

Agarwal, N. and Somaini, P. (2014). Demand analysis using strategic reports: An application to a school choice mechanism. NBER Working Paper 20775.

Arnosti, N. (2015). Short lists in centralized clearinghouses. In progress.

Calsamiglia, C., Fu, C., and Guell, M. (2014). Structural estimation of a model of school choices: The Boston mechanism vs. its alternatives. Unpublished working paper.

Calsamiglia, C., Haeringer, G., and Klijn, F. (2010). Constrained school choice: An experimental study. American Economic Review, 100(1):1860-1874.

Calsamiglia, C., Haeringer, G., and Klijn, F. (2011). A comment on: School choice: An experimental study. Journal of Economic Theory, 146:392-396.

Che, Y. and Kojima, F. (2010). Asymptotic equivalence of probabilistic serial and random priority mechanisms. Econometrica, 78(5):1625-1672.

Chen, Y. and Sönmez, T. (2006). School choice: an experimental study. Journal of Economic Theory, 127:202-231.

Cohen, L., De Jong, I., Jakobs, E., and Slot, J. (2012). Berlage or Barlaeus? het schoolkeuzeproces door de ogen van Amsterdamse ouders. Technical report, Bureau Onderzoek en Statistiek, Gemeente Amsterdam.

Erdil, A. and Ergin, H. (2008). What's the matter with tie-breaking? Improving efficiency in school choice. American Economic Review, 98(3):669-89.

Gale, D. and Shapley, L. (1962). College admissions and the stability of marriage. American Mathematical Monthly, 69:9-14.

He, Y. (2012). Gaming the Boston school choice mechanism in Beijing. mimeo University of Toulouse. 
Kojima, F. and Manea, M. (2010). Axioms for deferred acceptance. Econometrica, 78:633-653.

Roth, A. E. (2008). Deferred acceptance algorithms: History, theory, practice, and open questions. International Journal of Game Theory, 36:537-569. 


\section{Appendix A: Questionnaire (translated from Dutch)}

\section{Letter to parents/students}

Questionnaire application secondary education

This year, a research project is conducted to inquire whether the current assignment system can be improved. For this reason we ask you to fill out the attached questionnaire. The returned questionnaire has no influence on the application and admission procedure for a secondary school. The questionnaire should be returned in the attached envelop to the school where you apply, together with the application form. The questionnaire is immediately send to the researchers. The researchers are affiliated with the economics departments of the Free University Amsterdam and the University of Amsterdam. They are independent from the Amsterdam municipality and from the schools in Amsterdam. The researchers will report their findings in a report that will be publicly released. No information concerning individual students will be published.

Questions about this research project can be addressed to the researchers (Professor Pieter Gautier, Professor Hessel Oosterbeek or Professor Bas van der Klaauw) or to OSVO as representative of the boards of secondary schools in Amsterdam.

Signed with names and addresses of the researchers 


\section{Information student}

Name student:

Student number:

Name primary school

Advised level of secondary education

\section{Some questions about the application}

1. At which secondary school have you applied your child?

Name school:

2. Why have you applied your child at this school (mentioned in question 1)? You can indicate multiple reasons.

- It is a good school

- It is a nice school

- The school is close to home

- Older siblings are enrolled in the school

- Student has a high chance of being admitted

- School matches well with pedagogy of primary school

- Other, namely

3. Does your child have priority at the school where s/he applied?

yes/no

4. Do you think you run the risk of your child losing the lottery at the school where s/he applied?

yes/no

5. If so, how high do you consider the chance your child will lose the lottery? high/low

6. If no single school would conduct a lottery, would you then apply your child at another school?

yes/no 


\section{Preference list of secondary schools}

We would like to know your preferences for schools in case no single school would conduct a lottery. You should therefore not consider the possibility of losing a lottery. This may imply that you place another school at the first place than the school where you applied. You can only list schools that offer the level of education that corresponds with the recommended level of your child. Hence schools for which your child would qualify.

For each school we ask you to award points. The highest ranked school receives 100 points. The points you give to another school, can be seen as a percentage of the highest ranked school. The lower a school is on your list, the fewer points you award. If a school on the list is very close to the previous one, the the difference in points is small. For clarity we give some examples.

Below you can fill out your preferences regarding schools.

Preference list for schools (in accordance with advised school level):

\begin{tabular}{|l|c|}
\hline Name school & Number of points \\
\hline \hline $1 \ldots \ldots \ldots \ldots \ldots \ldots \ldots \ldots \ldots \ldots \ldots \ldots \ldots \ldots \ldots \ldots \ldots \ldots \ldots \ldots \ldots \ldots \ldots \ldots \ldots \ldots \ldots \ldots \ldots \ldots \ldots \ldots \ldots \ldots \ldots \ldots \ldots$ & \\
\hline 2. & \\
\hline 3. & \\
\hline 4. & \\
\hline 5. & \\
\hline 6. & \\
\hline 7. & \\
\hline 8. & \\
\hline 9. & \\
\hline 10. & \\
\hline
\end{tabular}

Finally we would like to know how many secondary schools you visited before you decided at which school to apply?

Number of schools visited: 


\section{Example preference list and awarding of points}

In this example, there are three students who each have to report their preferences regarding at most 10 schools (school A - school J).

Student 1 finds school A and school B equally good, school C is not so good but acceptable, he does not want to go to any of the other schools. Student 1 therefore gives 100 points to both school $\mathrm{A}$ and school $\mathrm{B}$ and 5 points to school $\mathrm{C}$. The other schools all receive zero points and do not have to be filled out.

Student 2 prefers school A. She values school E at $60 \%$ of school A. She values school $\mathrm{F}$ similar to school $\mathrm{E}$ and she therefore awards 60 points to schools $\mathrm{E}$ and $\mathrm{F}$. Schools C, D and J receive 30 points and the others schools 10 points.

Student 3 prefers school B and finds school C almost equally attractive. School $\mathrm{A}$ is valued lower than $\mathrm{C}$ and schools $\mathrm{G}$ and $\mathrm{J}$ even lower than A. Student 3 therefore values school $\mathrm{C}$ at $95 \%$ of school B, school A at $50 \%$ of school B and schools $\mathrm{G}$ and $\mathrm{J}$ at $10 \%$ of school B. Student 3 gives zero points to the other schools.

The preference lists of the students are therefore:

\begin{tabular}{|c|c|c|c|c|c|c|c|c|}
\hline \multicolumn{3}{|c|}{ Student 1} & \multicolumn{3}{|c|}{ Student 2} & \multicolumn{3}{|c|}{ Student 3} \\
\hline 1. & School A & 100 & 1. & School A & 100 & 1. & School B & 100 \\
\hline 2. & School B & 100 & 2. & School E & 60 & 2. & School C & 95 \\
\hline 3. & School C & 5 & 3. & School F & 60 & 3. & School A & 50 \\
\hline 4. & & & 4. & School C & 30 & 4. & School G & 10 \\
\hline 5. & & & 5. & School D & 30 & 5. & School J & 10 \\
\hline 6. & & & 6. & School J & 30 & 6. & & \\
\hline 7. & & & 7. & School G & 10 & 7. & & \\
\hline 8. & & & 8. & School H & 10 & 8. & & \\
\hline 9. & & & 9. & School B & 10 & 9. & & \\
\hline 10. & & & 10 & School I & 10 & 10 . & & \\
\hline
\end{tabular}

Please use the space below if you have any comments regarding this questionnaire or the application procedure. 


\section{Appendix B: Results from the Logit model used to create sam- pling weights and propensity scores.}

Table A1. Results Logit model

Dependent variable: Indicator for response to questionnaire

\begin{tabular}{lll}
\hline & Coefficient & se \\
\cline { 2 - 3 } Test score (scale 500-550) & 0.0242 & $(0.0177)$ \\
Test score unknown & 12.29 & $(9.703)$ \\
Girl (dummy) & $0.298^{* *}$ & $(0.107)$ \\
Gender unknown & $-1.948^{* *}$ & $(0.709)$ \\
constant & -10.78 & \\
School dummies: & yes & \\
Pseudo $R^{2}$ & & \\
LR $\chi_{32}^{2}$ & 0.1246 & \\
$N$ & 309.10 & \\
\hline
\end{tabular}

